\title{
BRINCAR É APRENDER: IMPORTÂNCIA DO LÚDICO NO PROCESSO ENSINO APRENDIZAGEM DOS ALUNOS DO ‥ ANO DO ENSINO FUNDAMENTAL
}

\author{
PLAYING IS LEARNING: THE IMPORTANCE OF LUDICIANS IN THE \\ TEACHING PROCESS LEARNING OF STUDENTS IN THE FIRST YEAR OF \\ FUNDAMENTAL EDUCATION
}

\section{Suély do Socorro Cunha de Freitas Alencar ${ }^{1}$}

RESUMO: Este artigo pretende refletir a cerca das formas de trabalho com o lúdico: A importância dos jogos e brincadeiras no r.o Ano do Ensino Fundamental. Ao tratar este assunto, o objetivo é mostrar aos educadores que é possível ensinar qualquer conteúdo de forma prazerosa para as crianças, pois ao brincar a criança estimula várias áreas do cérebro que faz com que ela aprenda a criar, imitar, aprender a respeitar limites, entre outras atividades a de se socializar, á qual se consideram de extrema importância. O artigo teve como abordagem diversos autores: (GILLES BROUGÈRE), (L.S VYGOTSKY), (JEAN CHATEAU) e (JEAN PIAGET). O referido estudo foi bibliográfico, e apresenta reflexões sobre a importância dos jogos, brinquedos e brincadeiras e que estas fazem parte do mundo da criança, pois estão presentes na humanidade desde o seu início. Logo, pretendeu-se contribuir para a compreensão que trata do resgate do lúdico como processo educativo, demonstrando que ao se trabalhar ludicamente não se está abandonando a seriedade e a importância dos conteúdos a serem apresentados à criança, pois as atividades lúdicas são indispensáveis para o seu desenvolvimento sadio e para a apreensão dos conhecimentos, uma vez que possibilitam o desenvolvimento da percepção, da imaginação, da fantasia e dos sentimentos. Por meio das atividades lúdicas, a criança comunica-se consigo mesma e com o mundo, aceita a existência dos outros, estabelece relações sociais, constrói conhecimentos, desenvolvendo-se integralmente.

PALAVRAS-CHAVE: Brincadeiras. Jogos. Ensino Fundamental. Ludicidade.

ABSTRACT: This article aims to reflect on the ways of working with play: The importance of games and play in the ist year of elementary school. When dealing with this subject, the goal is to show educators that it is possible to teach any content in a pleasurable way for children, because by playing the child stimulates various areas of the brain that makes them learn to create, imitate, learn to respect limits, among other activities, that of socializing, which are considered of extreme importance. The article was approached by several authors: (GILLES BROUGÈRE), (L.S VYGOTSKY), (JEAN CHATEAU) and (JEAN PIAGET). This study was bibliographic, and presents reflections on the importance of games, toys and games and that these are part of the child's world, since they have been present in humanity since its beginning. Therefore, it was intended to contribute to the understanding that it deals with the rescue of playfulness as an educational process, demonstrating that when working playfully, the seriousness and importance of the contents to be presented to the child are not being abandoned, since playful activities are indispensable for the their healthy development and for the apprehension of knowledge, since they enable the development of perception, imagination, fantasy and feelings. Through playful activities, the child communicates with himself and with the world, accepts the existence of others, establishes social relationships, builds knowledge and develops fully.

\footnotetext{
${ }^{\text {I }}$ Pedagoga graduada pela Universidade Estadual Vale do Acaraú-UVA. Pós-graduada em educação especial pelas Faculdades Integradas Ipiranga.suely.s.c.freitas@gmail.com.
} 
KEYWORDS: Play. Games. Elementary Education. Playfulness.

\section{INTRODUÇÃO}

A pesquisa intitulada Lúdico é eminentemente educativo no sentido em que constitui meios para desenvolver a curiosidade e o princípio de toda descoberta. Apresenta valores específicos para todas as fases da vida humana, assim na idade infantil e na adolescência a finalidade é essencialmente pedagógica.

Sabe-se que a situação escolar voltada para o lúdico é bastante comprometida e parece pouco estruturada sem uma função explicita na promoção dos processos de desenvolvimento. Dessa forma, a realidade dos alunos do $\mathrm{I}^{\mathrm{o}}$ ano do ensino fundamental torna-se conteudista, pois grande parte dos professores não estão desenvolvendo atividades voltadas para o lúdico.

É preciso reafirmar a necessidade de que a tarefa do profissional da educação passe a centrarse na brincadeira da criança e, com ela, resgatar a sua própria convivência lúdica. Com isto, pretendese mostrar uma visão das diferentes brincadeiras, pensando como um caminho de trabalho com a criança.

Na história da humanidade, encontra-se o brincar como atividade que sempre esteve na vida do ser humano e, em especial, na vida da criança. Foram manifestações que se perpetuaram, mas, por outro lado, eram sempre consideradas atividades com conotação pejorativa, e não relevantes. Para tal levanta-se o seguinte problema: A escola possibilita o brincar e aprender no processo de aprendizagem dos alunos do $\mathrm{I}^{\mathrm{o}}$ ano do ensino fundamental?

A sala de aula tem entre outras características, o fato de se apresentar como coisa séria, não permitindo espaço para o divertimento; o rigor e a disciplina são mantidos em nome dos padrões institucionais, o que torna o ambiente infantil artificial, longe dos gostos das crianças. O brincar se resume em ouvir histórias ou cantar algumas músicas. A hora do recreio e a hora da saída se tornam os únicos momentos em que as crianças desnudam da responsabilidade da escola para permitir-se brincar e ser criança.

Diante disto, a escola precisa se dar conta que através do lúdico as crianças têm chances de crescerem e se adaptarem ao mundo coletivo. O lúdico deve ser considerado como parte integrante da vida do homem não só no aspecto de divertimento ou como forma de descarregar tensões, mas também como uma forma de penetrar no âmbito da realidade, inclusive na realidade social.

A questão fica sobre o fato das escolas afastarem o lúdico da vivência dos alunos em sala de aula ao invés de aproveitarem como instrumento facilitador da aprendizagem, o que demonstra uma postura que nega a cultura da criança.

A partir dessa ideia considera-se que a brincadeira não se limita à infância, ela permeia todas as etapas da vida humana. Logo, pode-se evidenciar a importância do brincar como atividade 
prazerosa que beneficia o desenvolvimento dos seus alunos, a partir de um novo olhar que compreende a dimensão imaginária, ou seja, uma dimensão que pode produzir o novo: os sonhos, os desejos, as expectativas e os mitos dos sujeitos envolvidos com uma determinada realidade.

Portanto, o ato de brincar é importante, é terapêutico, é prazeroso, e o prazer é o ponto fundamental da essência do equilíbrio humano. Logo, pode-se dizer que a brincadeira é uma necessidade interior, tanto da criança quanto do adulto. No brincar, ocorre um processo de troca, partilha, confronto e negociação, gerando momentos de desequilíbrio, e propiciando novas conquistas individuais e coletivas. Com isso, a ação de brincar é fonte de prazer e ao mesmo tempo, de conhecimento.

Além disso, o ato de brincar pode incorporar valores morais e culturais em que as atividades devem visar à autoestima, o autoconhecimento, a cooperação, porque estes conduzem à imaginação, fantasia, criatividade, criticidade e a uma porção de vantagens que ajudam a modelar suas vidas, como crianças e como adultos. Partindo do pressuposto de que o lúdico é uma necessidade importante para o desenvolvimento do ser humano, entende-se que o professor deverá utilizar a brincadeira como um princípio norteador das atividades didático-pedagógico, encontrando significado para a ludicidade presente na relação que as crianças mantêm com o mundo.

Assim, as atividades lúdicas constituem-se de jogos, brincadeiras, que podem ser praticadas livremente pelas crianças ou direcionadas pelo professor. A principal importância do lúdico na educação fundamental tem como características constante do jogo e do brinquedo, que tem sua parte integral de influências significativas para o processo de desenvolvimento físico e intelectual na criança proporcionando-lhe a oportunidade para desenvolvê-lo-se através das relações sócioculturais.

O professor deve favorecer uma melhor possibilidade e compreensão do conhecimento lúdico, na qual ele poderá visar alcançar todos os aspectos, entre eles o sensório-mortor, o cognitivo, o afetivo e o sócio-cultural. Assim, têm-se os seguintes questionamentos: A escola proporciona cursos, treinamentos, palestras e seminários sobre a ludicidade?; Como os professores estão trabalhando com as atividades lúdicas no $\mathrm{I}^{\mathrm{o}}$ ano do ensino fundamental?; O lúdico favorece um bom rendimento na aprendizagem?

Considerando a importância do lúdico dentro da sala de aula, observa-se que ainda é muito insignificante o número de professores que se encaixam neste processo de construção para um melhor desempenho relacionado ao nível de aprendizado do aluno. Analisando este processo relacionado ao lúdico, percebe-se a necessidade de abranger a todas às escolas para que possam desde já começar a trabalhar essa questão lúdica dentro de sala.

Entende-se que é relevante o número de questionamentos que se têm relacionados à aprendizagem não absorvidas mesmo por falta de mecanismos repassados pelos docentes, estes que em certos casos se negam a estarem adequados em relação à questão do fazer de sua aula, um 
momento tanto de brincadeiras quanto de aprendizagem.

Quando se propõe uma brincadeira, deve-se ter comprometimento com várias áreas do conhecimento e com os conceitos ali presentes que podem estar ligadas à língua, à lógica, ao espaço, ao tempo, ao social e ao emocional. As situações postas nas brincadeiras, assim como as resoluções das situações problemas, podem gerar uma síntese integradora que fortalecem e amadurecem as crianças.

Atualmente, o brincar é visto como uma das atividades mais importantes da infância, como apoio de estudos de diversos autores. Ressalta-se que as brincadeiras são importantes na construção do conhecimento, mas as brincadeiras com regras por sua aplicabilidade de coincidir com a fase escolar em que os adjetivos são de extrema valia como estratégia de trabalho para o professor.

Isso se deve ao pressuposto de que a criança faz grande esforço no sentido de compreender o real que se apresenta e a brincadeira aproxima-se dos objetos de conhecimento a serem assimilados, de forma prazerosa e desafiadora. Constatando todas as problemáticas, acredita-se que é extremamente necessário que haja projetos específicos para cada situação, pois é preciso buscar soluções urgentes para o desempenho dos docentes em sala de aula. No presente artigo, far-se-á uma reflexão teórica a respeito do lúdico como elemento fundamental no processo de apropriação do conhecimento. Delimita-se a problemática para o ${ }^{\circ}$ ano do Ensino Fundamental.

O foco central é mostrar os vários aspectos do jogo como fonte impulsionadora do processo e desenvolvimento e da aprendizagem da criança. Neste sentido, pela característica da pesquisa bibliográfica, busca-se trazer à tona as ideias fundamentais dos diferentes papeis que tanto a brincadeira quanto o jogo exercem no fazer pedagógico.

\section{HISTÓRICO DO LÚDICO}

O lúdico advém do século XVI, e os primeiros estudos foram realizados em Roma e Grécia, destinados ao aprendizado das letras. Esse interesse decresceu com o advento do cristianismo, que visava uma educação disciplinadora, com memorização e obediência. A partir daí, os jogos são vistos como delituosos que levam a prostituição e a embriaguez. É no Renascimento que o jogo perde esse caráter de reprovação e entra no cotidiano dos jovens como diversão.

A palavra jogo, do latim "incus" quer dizer diversão, brincadeira. As definições mais gerais que se encontra nos dicionários de Língua Portuguesa são: “divertimento, distração, passatempo". Assim, a palavra jogo tanto é usada, por exemplo, para definir a atividade individual da criança na construção com blocos, como atividades em grupo de canto ou dança. A introdução à brincadeira em seu contexto infantil, inicia-se, timidamente, com a criação dos jardins de infância, fruto da proposta de Froebel.

Com o aparecimento da companhia de Jesus (uma organização religiosa inspirada em moldes 
militares, decididos a lutar em prol do catolicismo e que utilizaram o processo educacional como sua arma), o jogo educativo passou a ser um recurso auxiliar de ensino, vindo a expandir a partir de então. A seguir, aborda-se o jogo e cultura.

\subsection{O LÚDICO E SUA IMPORTÂNCIA NO PROCESSO EDUCACIONAL}

Numa viagem sempre se têm a pretensão de ir para algum lugar, mas não se pode deixar de mencionar um ponto importante, o de arrumar as malas, saber o que levar e o que deixar e ter em mente, que não se pode levar tudo, somente o essencial e assim mesmo ter consciência de que até o que se poderá sofrer modificações no decorrer da viagem, proporcionando novos conhecimentos, desenvolvendo-os cada vez mais. E a partir de agora inicia-se a viagem, e sim aquela que levará a um caminho de entendimentos sobre a educação básica, principalmente no $\mathrm{I}^{\mathrm{O}}$ ano do ensino fundamental e sua relação com o lúdico.

A educação infantil é sem sombra de dúvidas o ponto de partida para se refletir acerca da utilização do lúdico no processo educativo. Constituindo-se na primeira etapa da educação básica, desenvolvendo as bases da personalidade humana, da inteligência, da vida emocional, da socialização.

As primeiras experiências da vida são as que marcam mais profundamente as pessoas. Quando positivas, tendem a reforçar ao longo da vida as atividades de autoconfiança, de cooperação, solidariedade, responsabilidade, a educação torna-se essencial para o desenvolvimento do homem, em todas as esferas do emocional ao cognitivo, onde inaugura a educação da pessoa.

Em vista disso, a criança ao ingressar na Educação Infantil começa a ter noções básicas de conhecimento que poderão auxiliá-la em sua vida familiar, onde por meio de atividades lúdicas aprende ainda mais, pois tais atividades educam de forma criativa.

As atividades lúdicas possuem um papel importante no processo educativo porque englobam por completo o que diz respeito à criança à medida que, ao brincar esta também aprende a conhecer o mundo em que está inserida. Tal pensamento infelizmente não é comum à maioria dos adultos, pois para eles o lúdico continua sendo somente um passatempo, uma diversão sem fins educacionais. Mas será que isso procede? Realmente, o lúdico não educa? Existe relação entre o lúdico e a educação?

São tantos os questionamentos que surgem que às vezes ficam nos indagando o porquê de tantas discussões a respeito de uma questão que apresenta ser tão simples e ao mesmo tempo tão complexa, o de ensinar através do prazer, através do lúdico.

A reflexão sobre o ensinar por meio das atividades lúdicas, ganha posição importante nos debates que ocorrem atualmente entre os educadores envolvidos com a educação infantil, como também com os que atuam em outros níveis educacionais, pois para trabalhar no processo educacional requer uma preparação pedagógica e dentro dessa preparação o trabalho com o lúdico surge intrinsecamente ligado à educação.

A formação dos profissionais da educação infantil merecera uma atenção especial, dada à 
relevância de sua atuação como mediadores no processo de desenvolvimento e aprendizagem na fase introdutória da vida escolar das crianças. A qualificação especifica inclui o conhecimento das bases cientificas do desenvolvimento da criança, da produção do conhecimento e a habilidade de reflexão sobre a prática, de sorte que este se torne, cada vez mais fonte de conhecimento e habilidades na educação das crianças.

Além da formação acadêmica inicial, requer-se a formação permanente, inserida no trabalho pedagógico, nutrindo-se dele e renovando-o constantemente.

$\mathrm{Na}$ formação do educador, o trabalho com o lúdico deve ser abordado para o desenvolvimento da compreensão de que serve não somente para distrair, e sim para educar. A formação do educador ganharia em qualidade se em sua sustentação estivessem presentes três pilares: a formação teórica, a formação pedagógica e como inovação à formação lúdica.

É interessante ressaltar que a criança é um ser que pensa, sente e expressa-se de várias formas, uma delas é brincando. E esse brincar concretiza-se quando realiza as diversas atividades lúdicas (desenhos, pintura, danças, jogos, brincadeiras), a partir de então, o lúdico se constitui num fator de desenvolvimento que abrange tanto os aspectos sensório-motor, quanto o emocional, o afetivo e o cognitivo.

Percebe-se, portanto que o lúdico possui um caráter educativo, contrapondo assim, as ideias do senso comum quando afirma que o brincar não tem importância, por se tratar de brincadeira e passatempo. Nesse aspecto vem efetuar tal ideia quando enfatiza que: "o brincar é para a criança pequena, o que o trabalho deveria ser para o adulto: fonte de autodescoberta, prazer e crescimento".

Verifica-se assim que as atividades lúdicas proporcionam mais do que um simples entretenimento contribuindo de forma significativa no processo de aprendizagem por meio do encanto, unindo o útil ao agradável, à medida que:

\section{Segundo Brougère (2000):}

A criança precisa de espaço não somente o físico, mas o da criatividade, no qual possa aprender e assimilar com liberdade, pois o brincar é também um grande canal para o aprendizado, senão o único canal para verdadeiros processos cognitivos.

Assim sendo, não se deve deixar de utilizar o lúdico dentro do espaço escolar, haja vista que, por meio deste, tornar-se-á o conhecimento mais acessível às crianças. O brincar abre caminhos para a criança desenvolver o seu pensar perante aquilo que deseja aprender, para que desse modo, possa evidenciar aos adultos que está apta a construir conhecimentos. Visto desse modo, o lúdico proporciona a criança uma aprendizagem deleitosa do conhecimento que está sendo adquirido, dentro do ambiente escolar, onde, não somente a criança, mas também os educadores vivenciam uma maneira interativa e agradável, de empreender o processo do ensino e aprendizagem.

Para Brougère (198I): A brincadeira aparece como a atividade que permite à criança a 
apropriação dos códigos culturais e seu papel na socialização.

Continua o autor:

Encaramos a socialização como o conjunto dos processos que permitem à criança se integra aos "socius" que acerca assimilando seus códigos, o que lhe permite instaurar uma comunicação com os outros membros da sociedade tanto no plano verbal quanto no não- verbal. Acontece que pensamos que numa sociedade onde os objetos são, não só cada vez mais numerosos, mas também cada vez mais pregnantes, indispensáveis em numerosas situações de comunicação, mediadores onipresentes, eles também são vetores importantes no processo de socialização, muitos particularmentes através dos brinquedos, que são objetos específicos da infância.

Este pensar vem resgatar o lúdico como meio pelo qual o homem expressa o seu ser criativo, emocional e social. Demonstrando que não se pode deixar de utilizar as brincadeiras, os jogos, os brinquedos, as musicas, poesias, assim como as demais atividades lúdicas que fazem parte de vida do ser humano, por se constituir parte integrante da existência humana.

Usualmente as tarefas denominadas "sérias" estão intimamente ligadas com a obrigatoriedade de fazê- las, consideradas rotineiras, enfadonhas, no entanto necessárias e imprescindível de serem realizadas. Por outro lado, as atividades caracterizadas pelo lazer, diversão, não soa necessariamente aliadas a obrigação de realizar, no entanto a sua efetivação demanda prazer, alegria, contentamento.

O ser humano quando criança brinca, quando adulto faz uso da ludicidade para que o aprendizado se dê de forma efetiva, e porque na fase escolar não haveria de existir a presença do lúdico? O interessante é que a necessidade do lúdico já era percebida na antiguidade. No entanto na atualidade, ainda encontra-se muitos professores que realizam distinção muito grande entre o estudar-aprender e atividades lúdicas, como se estes estivessem totalmente dissociados do mundo infantil.

Existe, ainda, a situação em que o jogo é utilizado como metodologia, mas a forma como é evidenciado se torna tão mecânica que o professor age como se estivesse ditando um manual de instruções, nessa situação a atividade não proporciona o encantamento e a criança passa a sentir-se enfadada e começa a negar-se a participar, pois se decepciona com o que encontra, buscando algo bem diferente do que ora vivencia.

Por outro lado, não se trata de evidenciar o lúdico com um fim em si mesmo, pois a escola perderia o seu objetivo ao realizar algo totalmente dissociado da sua pratica educativa, seria uma atividade realizável na escola ou em qualquer outro lugar e não teria o seu diferencial no cotidiano do aluno, portanto é imprescindível um objetivo além do jogo.

Brougère (198I) afirma que:

A interação lúdica associa-se as significações preexistentes e aos estímulos inscritos nos brinquedos uma produção de sentido e de ação que emana da criança. É o momento em que a criança se apropria dos conteúdos disponíveis tornando-os seus, 
através de uma construção específica, que ela seja ou não original.

Sendo, portanto imprescindível à associação das atividades lúdicas com objetivos educativos visados para o aperfeiçoamento do ser humano como social e atuante na sociedade de que faz parte.

A criança aprende na interação com o outro, e muitas vezes ela busca de forma rápida a cheia de ânsias livrarem-se das tarefas-deveres para obter tempo livre para utilizá-lo na pratica do jogo, nesta fuga da realidade a criança transforma as suas aquisições em cultura, quando escapamos à realidade produzimos cultura, sem dúvida alguma essa cultura é sempre produzida na atividade lúdica.

O ser humano apresenta uma tendência lúdica, portanto o lúdico corresponde a um impulso natural da criança para satisfazes uma necessidade interior.

Para Brougère (1992):

O ensino, absorvido de maneira lúdica, passa a adquirir um aspecto significativo e efetivo no curso do desenvolvimento da inteligência já que ele se modifica de ato puramente transmissor a ato transformado em ludicidade, denotando-se, portanto em jogo.

Levando-se em consideração que o ensino lúdico é um recurso extremamente importante na educação, pois essa maneira lúdica de ensinar passa a ter um significado especial para a criança, no decorrer da aprendizagem, ela não vê mais o ensino como uma obrigação, mas como algo agradável, assim como assistir ao desenho predileto fluirá um forte teor de motivação, capaz de gerar um estado de vibração e euforia.

Vale ressaltar que as atividades lúdicas não estão relacionadas somente com o ato de brincar, mas principalmente com o desenvolvimento físico, cognitivo, afetivo, moral e social que se processa durante sua execução. Portanto é com o desenvolvimento global e harmônico da criança que cabe ao educador integrar-lhe ao universo da ludicidade, através de brincadeiras e jogos dentro do processo de ensino aprendizagem como um recurso pedagógico, pois sabe-se que o jogo está presente na escola, quer o professor permita, quer não.

Dessa maneira, percebe-se que é fundamental resgatar nos educadores o conhecimento do lúdico no processo de construção do conhecimento da criança dentro das escolas, pois este é inerente a criança e causa- lhe deleite e satisfação no ato de aprender.

Portanto, essas colocações são aqui efetuadas, não no sentido de desviarem a atenção para a especificidade da dominação, em termos, também de faixa etária, que inclusive a transcende, considerar a igualdade provocada pelo furto do lúdico na cultura da criança, é denunciar a relação de dominação existente. Implica, assim, no não isolamento da criança num mundo só seu, mas sim na sua consideração como parte da sociedade. "A pratica do lúdico educa, sempre sobre alguma coisa".

Porém além do valor educacional, que lhe é inerente, o lúdico tem sido utilizado como recurso pedagógico. Várias são as raízes que levam os educadores a recorrerem ao lúdico e a utilizá-lo como 
um recurso no ensino-aprendizagem. A visão do mundo lúdico por alguns autores evidencia a sua existência relacionada ao da criança, havendo uma forte união entre ambos, ocasionando no surgimento de novas concepções a respeito dessa relação.

Essas concepções proporcionam ao lúdico um destaque no meio educacional infantil, pois o que antes tinha a função de recreação, para muitos adultos, passa a assumir compromissos educacionais, visando o desenvolvimento emocional, social e cognitivo das crianças dentro do espaço escolar. Não se pode desprezar a satisfação que o lúdico nos proporciona, que é a do viver uma educação com prazer e desalienante. O estudar prazerosamente promovera nas crianças experiências inesquecíveis e únicas, onde o lúdico é apenas o instrumento para se obter um ensino e uma aprendizagem alicerçados na alegria e na satisfação. Em busca de uma educação com sabor.

A utilização das atividades lúdicas no espaço escolar ultrapassa a simples diversão, pois se constitui um mediador entre a criança e o conhecimento, devido contemplar motivação, a atuação criativa e a interação entre os sujeitos, e deste com o mundo. O brincar assume um papel abrangente e significativo no processo educativo, porque desperta a curiosidade no sujeito, e isso é essencial para torná-lo construtor do seu conhecimento.

O ambiente de sala de aula é um lugar de alegria, criatividade, de funções e de boas ações e relações sociais, onde cada criança possa desenvolver suas potencialidades brilhantemente.

O brincar faz parte da cultura da criança. Chateau (1987) ao falar da importância do lúdico para a criança explica:

O primeiro e fundamental aspecto sobre sua importância é que o brinquedo, jogo, a brincadeira, são gostosos, dão prazer, trazem felicidade. E nenhum outro motivo precisaria ser acrescentado para afirmar a sua necessidade. Mas deve-se considerar também que, através do prazer, o brincar possibilita a criança a vivencia de sua faixa etária e ainda contribui de modo significativo, para a sua formação como ser humano participante da cultura da sociedade em que vive, e não apenas como mero individuo requerido pelos padrões de produtividade social, a vivencia do lúdico é imprescindível em termos de participação cultural critica. Por tudo isso é fundamental que se assegure à criança tempo e o espaço para que o lúdico seja vivenciado com a base sólida da criatividade e da participação cultural, e, sobretudo, para o exercício do prazer de viver.

Propiciar um ambiente lúdico na escola contribuirá para que o fizer pedagógico parta das necessidades da criança, de sua cultura e assim inseri-la no mundo de novos saberes educativo a serem apreendidos e que tenha significação à sua vida sociocultural. Dando assim condições para que ela construa, com mais confiança, na escola e nas suas potencialidades, sua própria autonomia crítica e criativa, consciente de que os conhecimentos trabalhados de formas interdisciplinar na geografia, ciência, matemática e outras disciplinas, contribuirão para sua melhor atuação na sociedade.

Partindo dessa perspectiva, infere-se que o brincar é o canal capaz de tornar a escola espaço de construção de sujeitos críticos, criativos e ativos, baseado numa ação educativa, principalmente 
de sala de aula, de anulação do autoritarismo, opressão, submissão e dos momentos estafantes do ensino, dando vez à alegria, deleite, as atividades lúdicas.

Nesse sentido, fazer da sala de aula um espaço constitutivo da cultura da criança, recheado de para- lendas, cantigas de roda, de fabricação de pipas, de desenhos e pinturas, de jogos variados, da amarelinha, da poesia, da música e tantas outras formas lúdicas, que possam ser englobadas na escola, para que o processo ensino-aprendizagem decorra entre o prazer e o ato criador.

Isso não significa que a criança vai só brincar, mas que as atividades lúdicas possam fazer parte da educação escolar e que a sala de aula seja um ambiente lúdico, como garantia da interação entre os sujeitos envolvidos (professor e aluno, aluno e aluno) e destes com o conhecimento. É na sala de aula que decorre boa parte do processo ensino-aprendizagem, sendo assim, faz-se necessário que ela se torne ambiente favorável para a educação escolar aconteça de fato, onde sujeitos e conhecimentos mantenham uma relação dialeticamente construtiva, mediados pelo lúdico, estabelecendo, dessa forma, a indissolúvel e imprescindível interação entre escola, criança, prazer e o saber cientifica condições indispensáveis para uma educação de qualidade.

É preciso rever o sentido e a natureza do lúdico na educação, é preciso superar a imagem de que a escola é apenas um depósito onde a criança deixa o adulto (pais) livre para desempenhar as tarefas do seu cotidiano. Hoje é mais do que necessário que busque um espaço onde a criança seja percebida como sujeito histórico social e cultural, para que junto com outros membros de seu grupo (outras crianças) possa ter condições de assimilar o conhecimento produzido culturalmente, transformando-o e construindo novos significados para a sua aprendizagem.

Porém, ao redimensionar a educação, é preciso ter o cuidado para não adotar determinada teoria de forma dogmática. É preciso considerar as várias concepções sobre o lúdico, para dar conta da complexidade do ato pedagógico. No entanto não se pode deixar de ressaltar a concepção sócia interacionista Vygotskroiy, como aquele que tem se preocupado em sugerir um novo paradigma, uma nova forma de ver a escola, o conhecimento, a criança, o brincar, o professor e a própria sociedade.

A visão Vygotskyana sobre o aprendizado anteceder o desenvolvimento, faz com que se reflita que é preciso buscar o aperfeiçoamento da forma como a escola ensina, e como a criança aprende e constrói seu conhecimento, pois é na interação com o mundo que a criança aprende. Portanto, o ato de ensinar não pode de forma alguma ficar circunscrito a um ato autoritário e unilateral, mas sim percebera criança como sujeito ativo.

Assim, o lúdico enquanto instrumento de imaginação e prazer torna-se fundamental para a educação, por que incide na zona de desenvolvimento proximal, principalmente no momento em que a criança busca superar o conhecimento já estabelecido, para produzir nova aprendizagem. Neste sentido a educação deve se tornar a expressão do desejo de liberdade e da capacidade de exploração dos mais variados aspectos do lúdico. Nessa expressão a valorização da criatividade de criança é 
imprescindível como uma forma de desenvolvimento da inteligência.

Portanto para que haja uma educação significativa é preciso ainda considerar a importância do lúdico e sua relevância no ato educativo. A atividade lúdica não deve ser vista como uma atividade secundaria ou passa tempo, mas sim ser valorizada e estimulada pela escola não só na educação infantil, mas sim nas demais séries principalmente no $\mathrm{I}$ - ano do ensino fundamental.

A educação, hoje, no contexto da educação brasileira vem sofrendo mudanças conceituais significativas. Os referencias curriculares nacionais já contemplam o lúdico como um grande avanço na maturidade da criança, pois é na brincadeira que a criança aprende a separar o que é real e o que é fantasia.

O lúdico constitui-se então em uma linguagem especificamente infantil, mas que mantém o vínculo com aquilo que é o não brincar, ou seja, o mundo real. Isto significa dizer que é através do brinquedo que há construção da consciência da diferença que existe entre o imaginário e a realidade imediata que fornece conteúdo para a brincadeira se realizar, possibilitando assim a assimilação da cultura socialmente organizada e estruturada. Estas mudanças conceituais sobre a atividade lúdica na educação fazem com que faça uma reflexão de que é preciso buscar suporte teórico, para que a pratica educativa esteja sendo constantemente reestruturada.

\subsubsection{JOGO E CULTURA}

O ser humano tem recebido várias designações: Homo sapiens porque tem como função vital o raciocínio para aprender e conhecer o mundo; Homo faber porque fabrica objetos e utensílios, e Homo ludens porque é capaz de dedicar-se à atividade lúdica, isto é, ao jogo. Assim, para Brougère (1992): A manipulação de brinquedos permite ao mesmo tempo, manipular os códigos culturais e sociais e projetar ou exprimir, por meio de comportamentos e dos discursos que o acompanham, uma relação individual com esse código.

$\mathrm{O}$ ato de jogar é tão antigo quanto ao próprio homem, pois este sempre manifestou uma tendência lúdica, isto é, um impulso para o jogo. Portanto, a ideia que se tem é que os jogos são normalmente incorporados à cultura de um povo, a própria cultura se forma e se desenvolve impulsionado pelo espírito lúdico.

Assim, compreende-se que o lúdico é uma atividade dominante na infância, e caracteriza-se por determinadas condições concretas da criança, ou seja, pela realidade que ela compreende. Essa elaboração de mundo leva a criança a se apropriar das funções sociais e das normas comportamentais inerentes a sua cultura. Portanto, para Brougère (2000): Toda socialização pressupõe a apropriação da cultura, a impregnação cultural, ou seja, o mecanismo pelo qual a criança passa, entre outras coisas, pela confrontação com imagens, com representações, com formas diversas e variadas.

Discorrer sobre manifestações lúdicas, remete-nos a pensar a criança, como se fosse ponto pacifico essa associação. Porém é sabido, que esta, não vivencia esse lúdico de forma plena. Lúdico 
aqui é entendido como uma categoria geral de todas as atividades que tem características de jogo, brinquedo e brincadeira.

Chateau (1987) afirma que:

A infância é, portanto, a aprendizagem necessária à idade adulta. Estudar na infância somente o crescimento, o desenvolvimento das funções sem considerar o brinquedo, seria negligenciar esse impulso irresistível pelo qual a criança modela sua própria estátua.

A brincadeira constitui-se então, em um espaço de interação e de confrontos de diferentes crianças. Logo para Chateau (1987): O jogo representa então para a criança o papel que o trabalho representa para o adulto. Como o adulto se sente forte por suas obras, a criança sente-se crescer com suas proezas lúdicas.

Sendo parte integrante da vida em geral, o jogo tem uma função vital para o indivíduo, não só para descarga de energia, mas principalmente como forma de assimilação da realidade, além de ser culturalmente útil para a sociedade como expressão de ideais comunitários. A seguir, aborda-se o jogo e trabalho.

\subsection{3 - JOGO E TRABALHO}

É comum opor-se o trabalho ao jogo, considerando o primeiro como uma "atividade séria", enquanto o jogo não estaria associado ao conceito de seriedade. Essa ideia refletiu-se na educação durante muito tempo, e apesar de alguns conceitos dos grandes educadores, a pedagogia tradicional sempre considerou o jogo como uma espécie de alteração mental ou, pelo menos, como uma pseudo - atividade, sem significação funcional e mesmo nociva às crianças, que ele desvia de seus deveres.

Segundo Chateau, na criança, o jogo é, antes de tudo, prazer. É também uma atividade séria em que o fingir, as estruturas ilusórias, o egocentrismo infantil, a exaltação, tem uma importância considerável.

De acordo com Vygotsky (1984): o brinquedo fornece a estrutura básica para as mudanças das necessidades e da consciência. Frente a essas reflexões pode-se afirmar que o processo de construção do aprendizado será efetivado mediante a participação da criança no brincar. O prazer como disse Vygotsky (1984), não é suficiente para justificar a importância do brincar. Possui, porém, um papel relevante juntamente com os outros fatores, uma vez que leva a criança a ter iniciativa. A criança é incapaz de separar, pelo menos a princípio, a realidade da fantasia; o brincar para a criança é uma coisa muito séria.

Alguns autores em particular os norte - americanos, tentando contrapor à conduta lúdica à conduta séria, dizem que o jogo seria desprovido de estrutura organizada, em posição às atividades consideradas "sérias" que seriam regulamentadas. Ora, a existência de jogos com regras já é um 
argumento suficiente para contradizer essa ideia.

O próprio jogo simbólico, como é chamado o jogo de ficção ou imaginação, também é uma forma de ordenar a realidade, embora de modo subjetivo, isto é, de acordo com os desejos, anseios e interesses do indivíduo. Para Piaget, a atividade lúdica supõe uma ordenação da realidade, seja ela subjetiva e intuitiva (como no caso o jogo de ficção ou imaginação), ou objetiva e consciente (como no caso de jogos com regras).

A diferenciação dicotômica entre trabalho e jogo nos parece um tanto artificial e ilusória, pois as fronteiras entre ambos não são rígidas, bem como o contraste entre jogo e seriedade não é decisivo nem imutável. Certas formas de jogo podem ser extraordinariamente sérias: os jogos infantis - o futebol e o xadrez, por exemplo, são executados dentro da mais profunda seriedade.

\section{MÉTODO}

Logo, este estudo foi constituído de levantamento bibliográfico em livros, revistas, dissertações que tratam do tema abordado e que serviu para montar a discussão e o resultado. A próxima etapa consistiu no estudo como suporte para adquirir informações da formação de professores, verificando a qualidade do ensino e a importância do brincar no $\mathrm{I}^{\mathrm{o}}$ ano do ensino fundamental. Analisou-se por meio de pesquisas que os alunos precisam vivenciar mais o brincar em sala de aula, fazendo esta relação entre os autores que se posicionam possibilitando inferências destacadas no próximo capítulo das discussões e resultados.

\section{DISCUSSÕES E RESULTADOS}

Os jogos podem ser classificados de diferentes formas, de acordo com o critério adotado. Vários são os autores que se dedicaram ao estudo do jogo, tentando explicar sua origem e apresentando uma alternativa. Entre eles podemos citar: Lev Semyonovich Vygotsky, Roger Caillois, Jean Chateau, Jean Piaget e Gilles Brougère. Transcrevem-se em seguida algumas dessas classificações, detendo-nos em especial, na classificação dos jogos elaborada por Piaget, devido as suas implicações educacionais.

Jean Piaget utilizou os seguintes procedimentos:

a) Observação e registro dos jogos praticados pelas crianças em casa, na escola e na rua, tentando relacionar o maior possível de jogos infantis.

b) Análise das classificações já existentes e aplicações conhecidas à relação de jogos coletados.

Tendo adotado como critério classificatório o grau de complexidade mental, Piaget verificou que existem, basicamente, três tipos de estruturas que caracterizam os jogos: o exercício, o símbolo e a regra. Assim sendo, ele distribuiu os jogos em três grandes categorias, cada uma delas correspondendo a um tipo de estrutura mental:

1 - Jogo do exercício sensório - motor.

2 - Jogo simbólico (de ficção ou

imaginação e de imitação). 
3-Jogo de regras.

Piaget elaborou uma "classificação genética baseada na evolução das estruturas", como ele mesmo diz, pois, as três classes acima citadas correspondem às três fases do desenvolvimento mental.

Estas categorias estão dispostas por ordem de complexidade crescente e abarcam desde o jogo sensório - motor elementar até o jogo social superior. No item que se segue, refere-se uma explicação mais detalhada de cada uma dessas categorias.

Como foi dito anteriormente, o ser humano possui uma tendência lúdica ou, como denominam alguns, um "impulso para o jogo". Mas, como se manifesta esta tendência ao longo do processo de desenvolvimento?

Vygotsky (1984) diz que: o jogo aproxima-se da arte, tendo em vista a necessidade de a criança criar para si mesmo o mundo às avessas para melhor compreendê-lo, atitude que também define a atividade artística.

O jogo é construtivo porque pressupõe uma ação do indivíduo sobre a realidade. É uma ação carregada de simbolismo, que dá sentido à própria ação, reforça a motivação e possibilita a criação de novas ações.

O estudo mais completo sobre a evolução do jogo na criança é de autoria de Jean Piaget, que verificou este impulso lúdico já nos primeiros meses de vida do bebê, na forma do chamado jogo de exercício sensório - motor; do segundo ao sexto ano de vida predomina sob forma de jogo simbólico, para se manifestar, a partir da etapa seguinte, através da prática do jogo de regras.

Existem, portanto, três formas básicas de atividade lúdica que caracterizam a evolução do jogo na criança, de acordo com a fase do desenvolvimento em que aparecem. Mas é preciso salientar que estas três modalidades de atividade lúdica podem coexistir de forma paralela no adulto.

I - Jogo sensório - motor:

A atividade lúdica surge, primeiramente, sob a forma de simples exercícios motores, dependendo para sua realização apenas da maturação do aparelho motor. Sua finalidade é tão somente o próprio prazer do funcionamento. Daí dizer-se que o que caracteriza este tipo de jogo é o prazer funcional.

Segundo Piaget, quase todos os esquemas sensórios - motores dão lugar a um exercício lúdico.

Para o autor, esses exercícios motores consistem na repetição de gestos e movimentos simples, com um valor exploratório: nos primeiros meses de vida, o bebê estica e recolhe os braços e as pernas, agita as mãos e os dedos, toca os objetos e os sacode, produzindo ruídos e sons.

Esses exercícios têm o valor exploratório porque a criança os realiza para explorar e exercitar os movimentos do próprio corpo, seu ritmo, cadencia e desembaraço, ou então para ver o efeito que sua ação vai produzir. 
É o caso das atividades em que a criança manipula objetos, tocando, deslocando, superpondo, montando e desmontando. Movimentando-se, a criança descobre os próprios gestos e os repete em busca de efeitos.

Embora os exercícios sensórios - motores constituam a forma inicial do jogo na criança, eles não são específicos dos dois primeiros anos ou da fase de condutas pré-verbais.

Eles reaparecem durante toda a infância e mesmo no adulto, "sempre que um novo poder ou uma nova capacidade são adquiridos": por exemplo, aos 5 ou 6 anos, a criança realiza este tipo de jogo ao pular com um pé só ou tentando saltar dois ou mais degraus da escada; aos io ou 12 anos tenta andar de bicicleta sem segurar no guidão.

Para exemplificar este tipo de conduta lúdica no adulto, pode-se citar o caso do indivíduo que acaba de adquirir, pela primeira vez, um aparelho de som ou um automóvel, e se diverte fazendo funcionar o aparelho ou passeando no carro, sem outra finalidade senão próprio prazer de "exercer seus novos poderes". Assim sendo, essa forma de atividade lúdica, embora caracterize o nascimento do jogo na criança na fase pré-verbal (de o a 2 anos), ultrapassa largamente os primeiros anos de infância.

2- Jogo simbólico:

No período compreendido entre os 2 e os 6 anos, a tendência lúdica se manifesta, predominantemente, sob a forma do jogo simbólico, isto é, jogo de ficção, ou imaginação, e de imitação.

Nesta categoria estão incluídos a metamorfose de objetos (por exemplo, um cabo de vassoura se transforma num cavalo, uma caixa de fósforo num carro e etc.), e o desempenho de papéis (brincar de mãe e filho, de professor e aluno, de médico e etc.).

O jogo simbólico se desenvolve a partir dos esquemas sensório-motores que, à medida que são interiorizados, dão origem à imitação e, posteriormente, à representação.

A função desse tipo de atividade lúdica, de acordo com Piaget, "consiste em satisfazer o eu por meio de uma transformação do real em função dos desejos: a criança que brinca de boneca refaz sua própria vida, corrigindo-a a sua maneira, e revive todos os prazeres ou conflitos, resolvendo-os, compensando-os, ou seja, completando a realidade através da ficção”.

Portanto, o jogo simbólico, de imaginação ou imitação, tem como função assimilar a realidade, seja através da liquidação de conflitos, da compensação de necessidades não satisfeitas, ou da simples inversão de papeis (principalmente no que se refere aos papéis de obediência e autoridade). É um transporte a um mundo de faz-de-conta, que possibilita à criança a realização de sonhos, medos e angustias, aliviando a tensão e a frustração.

O jogo simbólico é, simultaneamente, uma forma de assimilação do real e um meio de auto expressão, pois à medida que a criança brinca de casinha, representando os papéis de mãe, pai e filho, 
ou brinca de escola, reproduzindo os papéis de professor e aluno, ele está, ao mesmo tempo, criando novas cenas e também imitando situações reais por ela vivenciadas.

A criança tende a reproduzir nesses jogos as atitudes e as relações predominantes no seu meio ambiente: ela será autoritária ou liberal, carinhosa ou agressiva conforme o tratamento que recebe dos adultos com os quais convive.Assim sendo, é através desta conduta lúdica que a criança expressa e integra as experiências já vividas.

3 - Jogo de Regras:

A terceira forma de atividade lúdica a surgir é o jogo de regras, que começa a se manifestar por volta

dos cinco anos, mas se desenvolve principalmente na fase que vai dos 7 aos 12 anos predominando durante toda a vida do indivíduo.

Para Piaget, os jogos de regras são jogos de combinações sensório-motoras ou intelectuais, em que há competição dos indivíduos e regulamentados quer por um código transmitido de geração em geração, quer por acordos momentâneos.

O que caracteriza o jogo de regras, como o próprio nome diz, é o fato de ser regulamentado por meio de um conjunto sistemático de leis (as regras) que asseguram a reciprocidade dos meios empregados. É uma conduta lúdica que supõe relações sociais ou interindividuais, pois a regra é uma ordenação, uma regularidade imposta pelo grupo, sendo que sua violação é considerada uma falta.

Piaget diz que o jogo de regras é uma atividade lúdica do ser socializado e começa a ser praticado por volta dos sete anos, quando a criança “abandona o jogo egocêntrico das crianças menores, em proveito de uma aplicação efetiva de regras e do espírito de cooperação entre os jogadores".

Portanto, esta forma de jogo pressupõe a existência de parceiros, bem como de certas obrigações comuns, o que lhe confere um caráter eminentemente social. Logo, o jogo na criança, inicialmente egocêntrico e espontâneo, vai se tornando cada vez mais uma atividade social, na qual as relações interindividuais são fundamentais.

O jogo de regras é necessário para que as convenções sociais e os valores morais de uma cultura sejam transmitidos a seus membros.

Em seus estudos, Vygotsky (1984) estabelece que o jogo de regras aparece posteriormente ao jogo de papéis, uma vez que as regras regulam o comportamento da criança, exigindo maior ou menor atenção ao processo da atividade; o que já é possível em crianças maiores. A seguir, aborda-se o jogo como recurso pedagógico.

Tratando-se de uma intervenção pedagógica por meio de jogos, é importante destacar seu valor na aplicação à educação dos alunos do Io ano do ensino fundamental. Reconhecendo a importância do jogar na educação, Chateau (1987) sublinha que: Caso sua aplicação na escola seja 
reduzida a um simples divertimento, rebaixa-se a educação e a criança, porque se despreza essa parte de orgulho e de grandeza que dá seu caráter ao jogo humano.

Adverte o referido autor que, durante muito tempo, ficou obscura a ideia de que o jogo pudesse conduzir ao trabalho. Com o advento da escola nova, os pedagogos passaram a adotá-la. Contudo, é necessário cuidado na utilização pedagógica. Torna-se imprescindível esclarecer as relações mútuas entre o jogo e trabalho.

Afirma Chateau (1987, p. 68):

A escola deveria apoiar-se no jogo, tomar o comportamento lúdico como modelo para conformar, segundo ele, o comportamento escolar... mas a educação tem em certos pontos de se separar do comportamento lúdico... uma educação que se limitasse ao jogo isolaria o homem da vida, fazendo-o viver num mundo ilusório.

O jogo é uma atividade que tem valor educacional intrínseco. Mas além desse valor educacional, que lhe é inerente, o jogo tem sido utilizado como recurso pedagógico. Várias são as razões que levam os educadores a recorrer ao jogo e utilizá-lo como recurso no processo ensinoaprendizagem.

Vygotsky (1984) diz que: o brinquedo tem um papel importante, aquele de preencher uma atividade básica da criança, ou seja, ele é um motivo para a ação. O brinquedo não é apenas um objeto que as crianças usam para se divertirem e ocuparem o seu tempo, mas é um objeto capaz de ensinálas a torná-las felizes ao mesmo tempo.

Torna-se evidente a necessidade de compreender o jogo no contexto educativo em sua justa medida sem reduzi-lo a trabalho e também sem dicotomizá-lo.

Chateau (1987), afirma que:

[...] uma preparação para o trabalho, exercício, propedêutica. Se a criança brinca é porque ainda é incapaz de trabalhar; o jogo é apenas um substitutivo do trabalho. Não convém que esse substitutivo venha tomar o lugar da realidade. É pelo trabalho que a escola deve desembocar na vida.

Para esse autor, o jogo deve ser visto como um encaminhamento ao trabalho, uma ponte entre a infância e a vida adulta. Por outro lado, o autor enfatiza seu uso na escola pelas possibilidades que o contexto lúdico favorece a criança: o domínio de si, a criatividade, a afirmação da personalidade, o imprevisível. Chateau considera o jogo como uma atividade séria que nasce da vontade em que há um esforço e uma tarefa para se cumprir uma prova.

Por meio do jogo, a criança aprende o que é uma tarefa, organiza-se, porque há um programa imperativo que a si mesma se impõe com um caráter de obrigação moral. Ao jogar, a criança aceita um código lúdico com um contrato social implícito. Logo, o jogo corresponde a um impulso natural da criança, e neste sentido, satisfaz uma necessidade interior, pois o ser humano apresenta uma tendência lúdica. Logo, o que agrada à criança no jogo é a dificuldade e o desafio, passiveis de serem 
livremente superados. Para Piaget (1971): O jogo na escola tem importância quando revestido de seu significado funcional. Por isso, muitas vezes seu uso no ambiente escolar foi negligenciado por ser visto como uma atividade de descanso ou apenas o desgaste de um excesso de energia.

Segundo Piaget, por meio da atividade lúdica, a criança assimila ou interpreta a realidade a si própria, atribuindo, então ao jogo um valor educacional muito grande. Neste sentido, propõe-se que a escola possibilite um instrumental à criança para que, por meio de jogos, ela assimile essas realidades intelectuais, a fim de que estas mesmas realidades não permaneçam exteriores à sua inteligência.

Para uma adaptação a realidade, no dizer de Piaget, é preciso uma síntese entre assimilação e acomodação. $\mathrm{O}$ jogo, no qual prevalece à assimilação pela própria evolução interna, pouco a pouco se transforma em construções adaptadas, exigindo sempre mais de trabalho efetivo, ou seja, numa escola ativa, todas as transições espontâneas ocorrem entre o jogo e o trabalho.

A atitude de jogo apresenta dois elementos que a caracterizam: o prazer e o esforço espontâneo. Como já foi dito anteriormente, o jogo é prazer, pois sua principal característica é a capacidade de absorver o jogador de forma intensa e total, criando um clima de entusiasmo.

É este aspecto de envolvimento emocional que torna o jogo uma atividade com forte teor motivacional, capaz de gerar um estado de vibração e euforia. Em virtude dessa atmosfera de prazer dentro da qual se desenrola, o jogo é portador de um interesse intrínseco, canalizando as energias no sentido de um esforço total para a consecução de seu objetivo.

Portanto, o jogo é uma atividade excitante, mas também, esforço voluntário. Estes dois elementos coexistem em situação de jogo: o prazer conduzindo ao esforço espontâneo e o esforço intensificando o prazer. Daí ser o jogo uma atividade liberadora da espontaneidade, pois impele à ação.

A situação do jogo mobiliza os esquemas mentais: sendo uma atividade física e mental, o jogo aciona e ativa as funções psico-neurológicas e as operações mentais, estimulando o pensamento. Logo, o jogo já é por si uma forma de ordenação do tempo, do espaço e dos movimentos, sendo que esta ordenação se expressa principalmente através das regras.

Sabe-se que o jogo integra as várias dimensões da personalidade: afetiva, motora e cognitiva. Como atividade física e mental que mobiliza as funções e operações, o jogo aciona as esferas motora e cognitiva, e à medida que gera envolvimento emocional, apela para a esfera afetiva. Neste particular, o jogo se assemelha à atividade artística, como um elemento integrador dos vários aspectos da personalidade.

O ser que brinca e joga é, também, o ser que age, sente, pensa, aprende e se desenvolve.

\section{CONSIDERAÇÕES FINAIS}

Para a introdução dos jogos na escola é necessário inicialmente formar professores para uma 
inteira e consciente execução das atividades lúdicas, pois o sentido real, verdadeiro e funcional dos jogos só será garantido e alcançado se o educador tiver plena consciência do que está fazendo, ou seja, o que, com que e como ele pode contribui para a formação do educando com a utilização dos jogos.

Está-se vivendo na chamada era da informação, nunca as informações foram tão ágeis, volumosas e dinâmicas. As velocidades com que elas são produzidas e divulgadas é tão grande que chega quase a serem inapreensíveis aos órgãos dos sentidos de uma pessoa comum. Na medida em que as informações chegam mais rápidas até nós, os aparatos eletrônicos evoluem isto equivale afirmar que a nossa tecnologia evolui velozmente ficando assim mais atraente, tentadora e interessante; tornando-se assim difícil para o educador competir com esta tecnologia.

Entretanto não adianta criticar a evolução eletrônica, devemos verificar o porquê de ela chamar tanto a atenção de nossas crianças e isto não é tarefa difícil, basta atentamos para as expressões das crianças quando estão utilizando esses equipamentos, é nítida a estampa da alegria da satisfação, do gozo, do prazer.

O educador para obter sucesso com os educados deve primeiramente conquistá-los e este processo se dá na medidas em que eles conseguem transpor credibilidades aos educandos apresentados um trabalho comprometidos, responsável sério atraente e prazeroso. A escola, o educador, a aula deve se aliar ao prazer, tornar conta das nossas emoções.

Os educadores devem se esforçar para ter e manter um bom relacionamento amigável com os educandos, tendo em vista que quando os mesmos gostam do educador eles acabam se interessando pelo trabalho dele, o que ele mediatiza de conhecimento e consequentemente se esforçam para ter e manter um bom relacionamento amigável com os educandos, tendo em vista que quando os mesmos gostam do educador eles acabam se interessando pelo trabalho deles, o que ele mediatiza de conhecimento e consequentemente se esforçam para aprender cada vez mais e melhor até para não decepcionar o professor.

Quando o educador eleva a estima do educando, acredita, confia e trata-o sem conceitos préconcebidos, este tende a aumentar a permanência na escola. Um professor que trabalhe nesta perspectiva certamente irá despertar nos educandos a paixão pelos estudos fazendo com que eles próprios comecem a ir em busca do conhecimento e quando isso acontece, o educador pode ter certeza que a sua missão foi cumprida, pois ele mesmo se encarregará de ir em busca dos conhecimentos de que necessita e ao educador cabe os merecidíssimos parabéns porque ele conseguiu despertar, conscientizar e confiar no educando.

Pode-se afirmar que o fracasso da maioria das escolas reside no fato da não credibilidade dos educadores nos educandos. É como se o educando não tivesse condições de caminhar sozinho, è algo interessante. Ora a criança para aprender a andar deve ser colocada no chão para inicialmente aprender a engatinhar e depois acompanhada dos pais fazer os primeiros ensaios de equilíbrio sobre duas pernas, até chegar o momento que os pais devem deixá-las sozinhas para que ela possa tentar e 
descobrir que pode andar sem o auxílio direto de outras pessoas, nesse momento tombos e escorregões são normas até a criança conseguir certo equilíbrio e quando ela descobre que pode andar sozinha ninguém mais a segura. A escola deve deixar o educando tentar andar sozinha e de modo algum subestimá-lo.

Precisamos reavivar o sentido verdadeiro da escola, do educador, repensar as nossas práticas. E consequentemente a formação do educador. O processo de ensino-aprendizagem é permeado por ações pedagógicas que compreendem meios e recursos didáticos utilizados pelos educadores e também pelo educando, entretanto o educador deve estar muito atento ao modismo para não utilizar um material sem o devido conhecimento sobre o mesmo.

É primordial o educador conhecer o material do qual lança mão, saber manuseá-lo se identificar com ele e ter convicção da contribuição dele para a compreensão do conhecimento por parte do educando. Para isto é fundamental que o educador não se atire em uma prática de olhos fechados é necessário que ele tenha uma formação no assunto.

Quanto mais informações tiver a respeito dos jogos mais segurança terá na aplicação e execução dos mesmos. $\mathrm{Na}$ formação do educador é indispensável:

-Conhecer a natureza lúdica do jogo, para principalmente não cair no modismo;

-Conhecer o tipo de trabalho que estará executando para avaliar os meios para introdução dos jogos;

-Conhecer as causas e as consequências dos jogos para possíveis encaminhamentos;

- Conhecer as maneiras mais viáveis para introdução dos mesmos considerando os diversos aspectos da educação como a escola em si, a organização, o planejamento, execução e avaliação da qualidade;

-O educador ao trabalhar com os jogos deve ter alguns cuidados fundamentais como: - Caracterizar os educandos e o ambientes, ou seja, considerar a idades, sexo, cultura, interesse e recursos materiais respectivamente;

-Adequar os objetivos, pois jogos não são recursos para passar o tempo em sala de aula.

É impossível falar de jogos sem falar de lúdicos, tendo em vista que os jogos pedagógicos são atividades lúdicas, as quais têm como pressupostos a satisfação e o prazer. Através do lúdico o educando aprende a pensar, pois estimula as suas dificuldades cognitivas, trabalharem a atenção, a observação, a memória, a imaginação, o vocabulário, a criatividades, a criticidades, executa ensaios para se dominar melhor social e emocionalmente. Já os jogos pedagógicos são meios que contribuem para a concretização de certo objetivos específicos.

O educador sendo conhecedor da natureza da natureza dos jogos dos prós e contras da utilização dos mesmos e consecutivamente ter caracterizando os educandos, o ambiente e adequado os objetivos, poderá ser adequar à determinação do planejamento escolar a fim de que o conhecimento que será compartilhado com o educando possa ser facilitado.

Os jogos pedagógicos são de inestimável importância por auxiliar a compreensão de sistemas 
abstratos e formais, vale a pena ressaltar que as aulas expositivas conjugadas a recursos que envolvam satisfação e prazer são aulas trabalho-jogo, que praticamente por si só remontam o verdadeiro sentido da escola.

Para aplicar um jogo pedagógico é necessário que o educador esclareça, muito bem, as regras do mesmo, o que torna imprescindível uma boa comunicação, não é fácil alcançá-la, pois existem muitas atitudes que impedem a sua execução.

Por exemplo, devemos evitar as atitudes julgadoras, respeitar os limites e a individualidade de cada pessoa, um jogo pedagógico ao ser direcionado deve ter a frente uma pessoa alegre, prestativa, sincera para com o outro, interessada com o aprendizado do grupo, cautelosa ao realiza críticas, preocupada com a opinião dos participantes dos jogo, sendo de suma importância os participantes serem chamados pelo próprio nome

,caso o educador ainda não saiba o nome de todos os participantes, vale apenas utilizar-se de crachás com os devidos nomes para evitar constrangimentos.

Antes de desenvolver o jogo o educador poderá juntamente com o grupo levantar algumas atitudes básicas que norteiam que o bom andamento dos participantes, ficando o educador responsável por incentivar vivenciar sem criar um clima de competição.

No momento da execução do jogo o educador deve demonstrar segurança e confiança no que está fazendo, deve ser um dinamizador, ter cuidados para não atrapalhar a execução do jogo, evitar gritos e desvios de regras, uma vez que as regras comungam com objetivos, ser flexível e acompanhar desenvolvimento do jogo passo a passo.

A avaliação da atividade se constitui no planejamento e se constrói no desempenho dos alunos no desenvolvimento das atividades e na auto avaliação e avaliação também os colegas.

Os jogos não são instrumentos avaliativos, mas sim estratégias que oferecem ao educador e aos educados a possibilidades de estarem constatando o rendimento de aprendizagem do grupo. Então, é função do educador valorizar a participação de todos os envolvidos no jogo, algo interessante é a atribuição de conceitos para a somatória final da nota dos educados, porém tendo a cautela de não criar um clima de competição desagradável e negativa.

Já que os jogos não são instrumentos avaliativos o educador deve lançar mão dos instrumentos de avaliação que mais se adequar para a situação. Entretanto, e interessante que utilize os registros das atividades para obter mais respaldo sobre a mesma e realizar as devidas orientações aos educandos no que diz respeito principalmente à concentração, atenção, interesse, cooperação, a fim de que o mesmo possa receber a devida orientação melhorar e evoluir nestes aspectos.

Ao pensar na aprendizagem dos alunos da $\mathrm{I}^{\underline{a}}$ série do ensino fundamental, seu desenvolvimento, processos de interação, educação escolar não se pode deixar de mencionar sobre a vontade de aprender, o desejo em buscar e realizar a construção de conhecimento e acredita-se que pode ser resgatado através dos jogos em sua dimensão afetiva. 
Logo, sucesso e fracasso escolar estão diretamente relacionados com essa vontade de aprender. A educação escolar deve objetivar manter esses alunos em situação constante de aprendizagens, mas muitas vezes a correria do dia-a-dia acaba por abafar esse processo e torna o prazer pelo aprender cada vez mais complicado, deixando espaço para o fracasso na aprendizagem.

Sendo assim, ao desenvolver em sala de aula trabalho com jogos está não só desenvolvendo os aspectos cognitivos da criança, mas passando também a enfatizar os aspectos afetivos que são resgatados durante o momento lúdico (jogos e brincadeiras).

Chateau (1987) é um autor que valoriza o jogo, destacando a importância da observação de diferentes manifestações do ponto de vista afetivo, social, motor e moral:

No jogo a criança mostra, aliás, sua inteligência, sua vontade, seu traço dominante, sua personalidade, enfim. Todo pedagogo digno desse nome há muito esta atento a essas múltiplas indicações dadas pela maneira de jogar/brincar.

Para trabalhar com os jogos em todas as suas dimensões, tanto cognitivas quanto afetivas, tem-se que se traçar e definir os objetivos que se quer alcançar, para não ficar um momento solto e sem significado dentro da sala de aula.

Está-se então, interligando a educação escolar com a apropriação de conhecimentos, o que resulta em processos de aprendizagem e desenvolvimento. Assim, ao trabalhar com o lúdico e seus aspectos afetivos que norteiam o processo da aprendizagem pode-se buscar através de atividades significativas o sucesso escolar.

Desse modo, pode-se concluir que é fundamental querer conhecer os alunos e criar situações que possam convidá-los a crescer, a expressar seus sentimentos em relação ao conhecimento, tanto no que se refere às dificuldades quanto aos interesses. Em uma palavra, considera-se de grande valor o trabalho profissional que atua integrando - dentro do possível - os aspectos afetivos e cognitivos presentes nas diversas situações escolares.

Segundo Piaget (1971):

[...] uma criança não saberia dizer tudo a seu professor, uma vez que ela tem necessidade de ser bem vista, de passar por bom aluno, em suma, de pensar no seu futuro escolar. Ela procura então, antes de tudo, não dizer besteiras e agir de acordo com as saudáveis tradições da classe.

Um professor experiente e observador é capaz de antecipar sentimentos, imaginar dificuldades ou supor dúvidas que serão geradas no contexto de sala de aula. Ao dialogar com seus alunos, abrirá espaço para o surgimento de perguntas que, ao serem solucionadas, colaboram para aliviar a tensão e diminuir os medos.

Portanto, ao ensinar com carinho e respeito às individualidades e potencialidades esta-se mais próximo de prevenir os fracassos escolares. É ampliar a saúde educacional, é dar sentido ao que 
é realmente significante para quem quer aprender.

Aos educadores envolvidos com o processo de aprendizagem cabe resgatar nas crianças o gosto pelo aprender, à vontade pela busca de conhecimento. Considera-se então que através dos jogos isso se processa mais facilmente.

Assim, observar a criança como um sujeito pensante, orgânico, corporal, intelectual e simbólico é ponto de partida para uma nova concepção de aprendizagem, aquela que realmente buscará o sucesso.

O educador tem que ser um mediador e propor situações de jogos em sala de aula onde, o educando possa investigar e pesquisar. Logo, o professor ocasionará momentos de afetividade entre a criança e o aprender, tornando a aprendizagem formal mais significativa e prazerosa. Ainda sobre a relação entre os aspectos afetivos e cognitivos Piaget (1971) diz que: É incontestável que o afeto exerce um papel essencial no funcionamento da inteligência. Sem afeto não haveria interesse, necessidade, motivação e, conseqüentemente, não haveria inteligência.

A construção de um espaço de jogo, de interação e de criatividade proporcionará o aprender com o seu objetivo máximo, com sentido e significado, no qual o gostar e o querer estarão sempre presentes.

Quando os problemas de aprendizagem ou fracassos escolares ocorrem devido à anulação das capacidades e o bloqueio das possibilidades de aprendizagem a construção de situações mais significantes de ensino podem auxiliar na busca pelo sucesso escolar.

Logo, um aspecto da educação escolar que proporciona o sucesso escolar é o resgate do jogo, proporcionando um ambiente de amor, nas relações entre criança, conhecimento, meio, aprendizagem e educadores.

Trabalhar com a dimensão lúdica é muito mais do que brincar com as crianças é proporcionar espaços onde seus desejos e sentimentos, ou seja, sua afetividade esteja presente.

Ao negar-se o aprender ou rejeitar a aprendizagem, a criança se negará a participar de seu processo de desenvolvimento, o que dificultará cada vez mais as assimilações no processo educativo. O jogo será então a articulação entre o desejo, a afetividade, inteligência e os processos de apropriação do conhecimento.

Momentos de aprendizagem significativa que proporcione processos de desenvolvimento ressaltam o valor do sucesso escolar como algo verdadeiro e realmente importante para a criança. A relação entre educadores e educandos deve ser verdadeira e de troca de experiências e opiniões, favorecendo um clima harmônico para a socialização do conhecimento.

$\mathrm{O}$ uso de jogos pode auxiliar todo este processo, tanto no aspecto cognitivo quanto no aspecto afetivo. Somente ao relacionar-se com o saber, interar-se com o conhecimento é que se pode compreender o significado da aprendizagem.

A sala de aula deve ser um espaço de confiança, de liberdade (mas com limites), de conteúdos 
interdisciplinares, de inclusão, de aceitação do novo e da afetividade. É nesse espaço de interação que a aprendizagem irá ocorrer. Portanto, o sucesso escolar está na realização de um trabalho com prazer.

Jogar em sala de aula proporciona momentos ricos em interação e aprendizagem, auxiliando educadores e educandos no processo de ensino aprendizagem. O conhecimento é a apropriação do objeto de conhecimento, através das constantes alterações entre a criança, meio e objeto de conhecimento.

Portanto é no jogar que se cria, antecipa e inquieta, assim, transforma-se, levanta-se hipóteses e traça estratégias para a busca de soluções. No jogar, o desejável passa a ser algo obtido através de sua imaginação no qual o abstrato se concretiza e resulta no processo de construção do conhecimento.

As situações de jogos atuam no imaginário e estabelece regras, o que proporciona desenvolvimento na medida em que impulsionam conceitos e processos em desenvolvimento.

Analisa-se então, os jogos como uma estratégia de ensino, no qual ao agir a criança projeta seus sentimentos, vontades e desejos, buscando assim a afetividade na aprendizagem.

Portanto, acredita-se que os jogos podem também resgatar o desejo pela busca de conhecimento e tornar a aprendizagem prazerosa, na qual a criança passa a gostar cada vez mais de aprender.

\section{REFERÊNCIAS}

BROUGÈRE, Gilles. Brinquedo e cultura. 6ª ed. São Paulo: Cortez, 20o6. CHATEAU, Jean. O jogo e a criança. São Paulo: ummus: Papirus, 1987.

PIAGET, Jean. A formação do símbolo na criança. Rio de Janeiro: Zahar, I97ı.

VYGOTSKY, L.S. A formação social da mente. São Paulo: Martins Fontes, 1984. 